\title{
Thermal effects on weld and unweld tensile properties of injection moulded short glass fibre reinforced ABS composites
}

\author{
S. Hashemi* \\ London Metropolitan University, London Metropolitan Polymer Centre, Holloway Road, London N7 8DB, UK
}

Received 30 May 2007; accepted in revised form 20 August 2007

\begin{abstract}
The effect of temperature on weldline properties of injection moulded acrylonitrile butadiene styrene (ABS) reinforced with short glass fibres was investigated in tension between 25 and $100^{\circ} \mathrm{C}$. Tensile modulus of both weld and unweld specimens increased linearly with increasing fibre concentration and decreased linearly with increasing temperature. It was found that the presence of weldline had no significant effect upon tensile modulus and this was reflected by weldline integrity factors in the range 0.98 to 0.95 . Tensile strength of both weld and unweld tensile specimens increased nonlinearly with increasing fibre concentration and in the case of weldline specimens showed a maximum at fibre concentration of approximately $10 \% \mathrm{v} / \mathrm{v}$. A linear dependence with respect to volume fraction of fibres was found for specimens without weldline for fibre concentrations in the range $0-10 \% \mathrm{v} / \mathrm{v}$. The weldline integrity factor for tensile strength decreased significantly with increasing fibre concentration and increased with increasing temperature. The effect of temperature on tensile modulus and strength was satisfactorily modelled using the Kitagawa power law relationship.
\end{abstract}

Keywords: polymer composites, weldline, temperature

\section{Introduction}

It is well established that the mechanical properties of short fibre polymer composites such as strength and modulus are derived from a combination of the fibre and matrix properties and the ability to transfer stresses across the interface between the two constituents. These properties, however, are affected by a number of parameters, such as the fibre content, fibre length, fibre orientation and the degree of interfacial adhesion between the fibre and the matrix (e.g.: [1-15]). However, as most short fibre composites are fabricated by an injection moulding process, the presence of weldlines is a major design concern as weldlines could lead to a considerable reduction in mechanical properties and because of this designers often need to incorpo-

*Corresponding author, e-mail: s.hashemi@londonmet.ac.uk

(C) BME-PT and GTE rate liberal safety factors in design analysis to compensate for this weakness.

Weldlines are often observed in injection moulded components due to multigate moulding, existence of pins, inserts, variable wall thickness and jetting and are classified as either being cold or hot. The cold weldlines are formed when two melt fronts meet head on and this type of weld provides the worst-case scenario as far as mechanical properties are concerned. A serious reduction in tensile strength and modulus has been reported for many polymers and their composites in the presence of cold weldlines (e.g.: [1-12]). In general, the presence of a weldline reduces tensile strength by up to $60 \%$ and tensile modulus by up to $40 \%$ depending on the polymer, the characteristic features of the reinforcing filler and the processing conditions 
being used. For example, whilst addition of spherical shaped fillers (e.g. glass spheres) has shown to have little effect upon tensile strength of injection moulded thermoplastics with weldlines, addition of cylindrical shaped fillers (e.g. short fibres) has led to a considerable reduction in weldline strength due to the alignment of the fibres parallel to the weldline. The processing conditions such as melt temperature, injection speed and mould temperature could also play an important role in determining the integrity of the welded components and many studies have addressed this issue for both amorphous and semi-crystalline polymers (e.g.:[10, 11, 14])]. However, whilst the majority of weldline studies have been conducted at room temperature, very few have examined the integrity of weldlines at elevated temperatures, particularly in short fibre composite systems [3-5]. To this end, the present work was undertaken to examine the effect of temperature on tensile properties of ABS and its short glass fibre composites in the presence of weldline.

\section{Experimental}

\subsection{Materials}

Owens Corning chopped E-glass fibres of initial length and diameter of $4.0 \mathrm{~mm}$ and $10 \mu \mathrm{m}$, respectively was used as the reinforcing filler for Acrylonitrile Butadiene Styrene (ABS) copolymer received from BAYER. The ABS and the short glass fibres were compounded to produce a series of composites with nominal glass contents of 10, 20 and $30 \% \mathrm{w} / \mathrm{w}$.

\subsection{Compounding}

ABS and the short glass fibres were at first dry blended to the desired glass contents of 10,20 and
$30 \% \mathrm{w} / \mathrm{w}$. After drying in an oven at $80^{\circ} \mathrm{C}$ for 4 hours the melt compounding of $\mathrm{ABS}$ composites was carried out in a counter-rotating twin-screw extruder (Leistritz). The average screw speed was $60 \mathrm{rpm}$ and the die diameter was $4 \mathrm{~mm}$. The extrusion zone temperature ranged from $220-235^{\circ} \mathrm{C}$. The extrudates emerging from the die exit were continuously cooled in a water bath and pelletised for injection moulding. Prior to injection moulding, pellets were dried in an oven at $80^{\circ} \mathrm{C}$ for 4 hours.

\subsection{Specimen preparation}

The pellets were injection moulded into dumbbell shaped tensile bars using a Negri Bossi NB60 injection-moulding machine using the processing conditions listed in Table 1. The mould used consisted of a single and a double-feed cavity as shown in Figure 1, each $1.7 \mathrm{~mm}$ in depth. In the latter a weldline was formed as the two opposing melt fronts met mid-way along the gauge length of the specimen. The dimensions of weldline free specimens (WFS) and weldline specimens (WLS) are depicted in Figure 2.

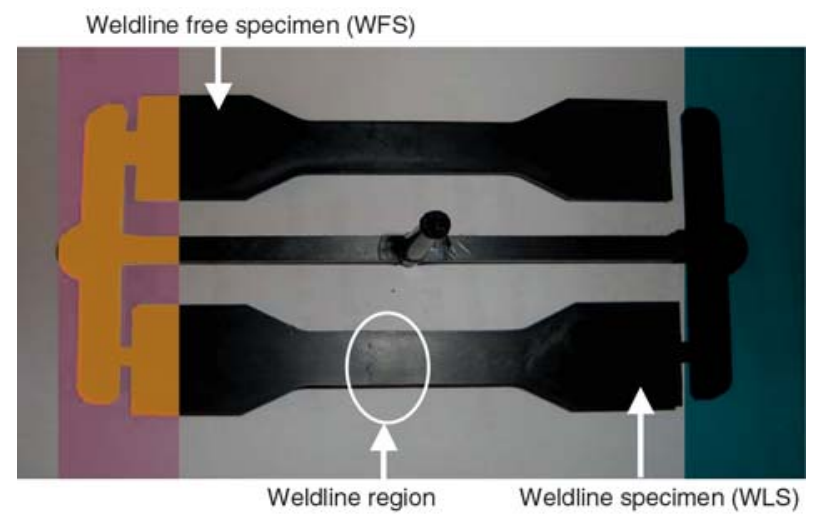

Figure 1. Weldline free (WFS) and unweld tensile specimens

Table 1. Injection moulding conditions for each composite

\begin{tabular}{|l|c|c|c|}
\hline \multicolumn{1}{|c|}{ Processing condition } & ABS & $\begin{array}{c}\text { Composite } \\
\text { with } \mathbf{1 0 \%} \text { glass fibre }\end{array}$ & $\begin{array}{c}\text { Composite } \\
\text { with 20\% }\end{array}$ \\
\hline glass fibre
\end{tabular}



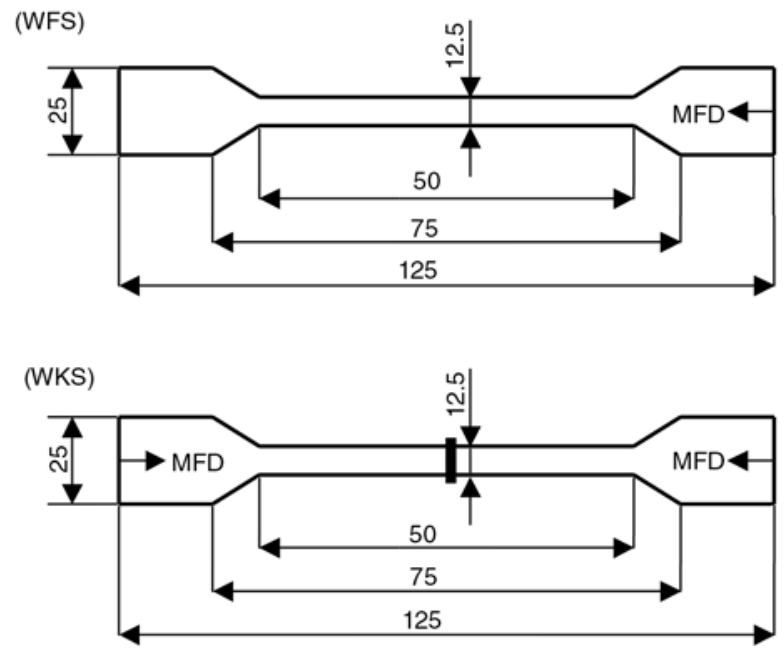

Figure 2. Dimensions of the WFS and WLS in millimetres

\subsection{Measurement of fibre length and fibre concentration}

Fibre concentration in each composite was determined from the fibre residue remained after ashing weighed samples cut from the gauge length of the moulded bars at $550^{\circ} \mathrm{C}$. After cooling, the ash of fibrous material was weighed and the exact weight fraction of fibres $\left(w_{f}\right)$ was determined. The $w_{f}$ values were subsequently converted into volume fractions $\left(\phi_{f}\right)$ using the Equation (1):

$\phi_{f}=\left[1+\frac{\rho_{f}}{\rho_{m}}\left(\frac{1}{w_{f}}-1\right)\right]^{-1}$

Taking the density of the matrix $\left(\rho_{m}\right)$ as $1.12 \mathrm{kgm}^{-3}$ and density of the fibre $\left(\rho_{f}\right)$ as $2.54 \mathrm{kgm}^{-3}$ gave fibre concentration values of $4.4,9.5$ and $15.5 \% \mathrm{v} / \mathrm{v}$. It must be pointed out that the void content in moulded specimens was not measured in this study. The residue from the ash tests were subsequently spread on a glass slide and placed on the observation stage of a microscope. Magnified fibre images were transmitted to a large screen, and the fibre images were then automatically digitised by software with a computer. From the fibre length distributions, the average fibre length values $\left(\overline{L_{f}}\right)$ of 110 , 94 and $83 \mu \mathrm{m}$ were obtained for $4.4,9.5$ and $15.5 \% \mathrm{v} / \mathrm{v}$ composites, respectively. Results show decrease in $\overline{L_{f}}$ with increasing $\phi_{f}$ thus indicating that the average length of the fibre in the moulded specimens was affected by the concentration level of the fibres. The increased damage to fibre length with increasing $\phi_{f}$ was attributed to a greater degree of fibre-fibre interaction and increased in melt viscosity at higher fibre loadings. The latter give rise to higher bending forces on the fibres during compounding and moulding process causing the fibres to break, as noted here.

\subsection{Mechanical testing}

Dumbbell specimens with weldline (WLS) and without weldline (WFS) were tested in tension in an Instron testing machine using pneumatic clamps. Tensile tests were performed at 25,60 and $100^{\circ} \mathrm{C}$ at a constant crosshead displacement rate of $50 \mathrm{~mm} / \mathrm{min}$. For each composite at least six specimens with weldline and six without weldline were tested at a given temperature. The load-displacement curve for each specimen was recorded using a computer data logger from which tensile modulus and strength were calculated using the initial slope and the load at maximum, respectively. The modulus values reported in this study are based on the displacement of the crosshead.

\section{Results and discussion}

\subsection{Tensile modulus}

\subsubsection{Effect of fibre concentration}

The load-displacement curves obtained indicated that the tensile behaviour of ABS and its composites during the early stages is linearly elastic. Figure 3 shows that composite modulus $\left(E_{c}\right)$ calculated using the initial slope of the load-displacement curves increases with increasing $\phi_{f}$. As illustrated in Figure 3, variation of $E_{c}$ with $\phi_{f}$ is extremely linear at all three temperatures. The linear dependence

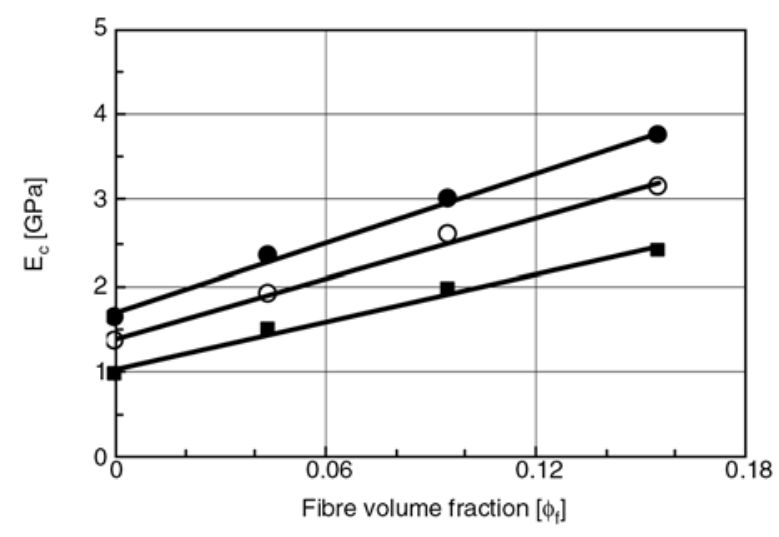

Figure 3. Effect of fibre volume fraction on tensile modulus of weldline free specimens (WFS) at $25(\bullet)$, 40 (o) and $100^{\circ} \mathrm{C} \mathrm{( \bullet )}$ 
Table 2.. Fibre efficiency parameters for composite modulus as a function of fibre volume fraction at 25,60 and $100^{\circ} \mathrm{C}$

\begin{tabular}{|c|c|c|c|c|c|c|c|c|c|}
\hline \multirow{2}{*}{$\phi_{\mathrm{f}}$} & \multicolumn{3}{|c|}{$\eta_{E}$} & \multicolumn{3}{|c|}{$\eta_{\mathbf{L}}$} & \multicolumn{3}{|c|}{$\eta_{0}$} \\
\hline & $25^{\circ} \mathrm{C}$ & $60^{\circ} \mathrm{C}$ & $100^{\circ} \mathrm{C}$ & $25^{\circ} \mathrm{C}$ & $60^{\circ} \mathrm{C}$ & $100^{\circ} \mathrm{C}$ & $25^{\circ} \mathrm{C}$ & $60^{\circ} \mathrm{C}$ & $100^{\circ} \mathrm{C}$ \\
\hline 0.044 & 0.200 & 0.173 & 0.133 & 0.296 & 0.261 & $\begin{array}{l}0.199 \\
\end{array}$ & 0.675 & 0.663 & 0.667 \\
\hline 0.095 & 0.200 & 0.173 & 0.133 & 0.296 & .0260 & 0.199 & 0.677 & 0.664 & 0.669 \\
\hline 0.155 & 0.200 & 0.173 & 0.133 & 0.294 & 0.259 & 0.197 & 0.681 & 0.669 & 0.674 \\
\hline
\end{tabular}

between $E_{c}$ and $\phi_{f}$ follows the modified 'rule-ofmixtures' given by Equation (2):

$E_{c}=E_{m}+\left(\eta_{E} E_{f}-E_{m}\right) \phi_{f}$

where $E_{m}$ is the modulus of the matrix and $E_{f}$ is the modulus of the fibre whose value in this study was taken as $76 \mathrm{GPa}$ and temperature independent. The parameter $\eta_{E}$ is termed the overall fibre efficiency for composite modulus whose value depends on the length and the orientation of the fibres in the moulded specimens. The value of $\eta_{E}$ was determined from the slope of the line $E_{c}$ versus $\phi_{f}$ in Figure 3 using Equation (2). Values obtained are given in Table 2 where it can be seen that $\eta_{E}$ decreases with increasing temperature.

The overall efficiency parameter $\eta_{E}$ is the product of two efficiency parameters; one associated with the orientation of the fibres $\left(\eta_{0}\right)$ and the other with the shortness of the fibre $\left(\eta_{L}\right)$. The parameter $\eta_{L}$ was evaluated using the Cox shear lag model [16] which gives $\eta_{L}$ by Equation (3):

$\eta_{L}=1-\frac{\tanh \beta}{\beta}$

where $\beta$ is defined by Equation (4):

$\beta=\frac{\bar{L}_{f}}{2}\left(\frac{4 E_{m}}{E_{f} d^{2} \ln \lambda}\right)^{\frac{1}{2}}$

where $d$ is the diameter of the fibres. If packing arrangement of fibres is assumed square, then $\lambda$ can be obtained from Equation (5):

$\lambda=\sqrt{\frac{\pi}{4 \phi_{f}}}$

Values of $\eta_{L}$ obtained are given in Table 2 where it can be seen that whilst $\eta_{L}$ is not affected by the concentration of the fibres, it decreases with increasing temperature. Also given in the table are values of $\eta_{0}$ obtained from the ratio $\eta_{E} / \eta_{L}$. The $\eta_{0}$ values range between 0.663 and 0.681 which are in the same range as $0.67-0.72$ reported for some polymer composite systems [2-4, 8, 9]. Using the Krenchel [17] definition of $\eta_{0}$ which is given by Equation (6) and assuming a perfect alignment of fibres (i. e. $a_{n}=1$ ), one obtains fibre orientation angle, $\theta$ of approximately 25 to $26^{\circ}$ with respect to loading direction.

$\eta_{0}=\sum_{i=1}^{i=n} a_{n} \cos ^{4} \theta_{n}$

\subsubsection{Effect of temperature}

Temperature dependence of $E_{c}$ is shown in Figure 4 where it can be seen that in the present temperature range, $E_{c}$ decreases linearly with increasing temperature at a rate which is dependent upon the concentration of fibres in the composite. Evidently, as $\phi_{f}$ increases so does the rate at which $E_{c}$ decreases with increasing temperature. The linear dependence between modulus and temperature can be expressed by Equation (7):

$E(T)=E_{0}-\kappa T$

where $E_{0}$ and $\kappa$ are constants whose values at a given temperature increased with increasing $\phi_{f}$.

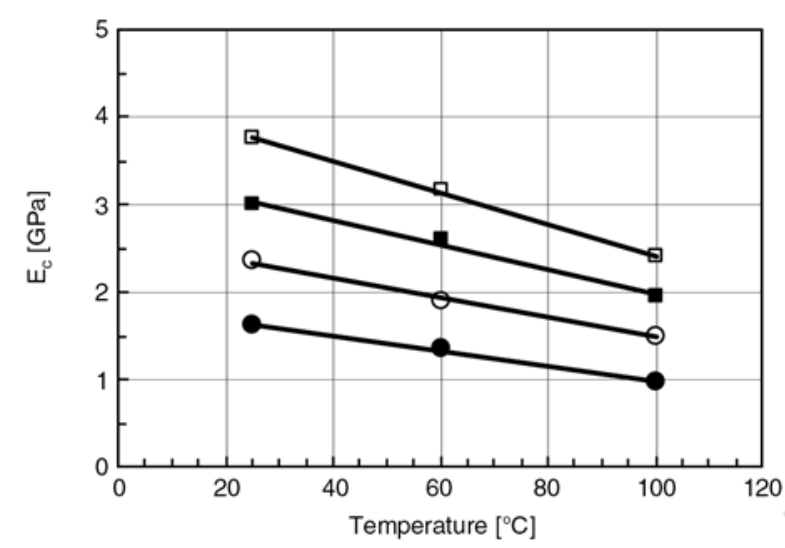

Figure 4. Effect of temperature on tensile modulus of weldline free specimens (WFS) with fibre concentration values (v/v) of $0 \%(\bullet), 4.4 \%$ (o), $9.5 \%(\bullet)$ and $15.5 \%(\square)$ 


\subsubsection{Effect of weldline}

It was noted that the initial slope of the load-displacement curves was marginally affected by the weldline. As shown in Figure 5, modulus of the weldline specimens $\left(E_{c w}\right)$ like weld free specimens $\left(E_{c}\right)$ increased linearly with increasing $\phi_{f}$. Using the slopes, $\eta_{E}$ values of $0.194,0.168$ and 0.137 were obtained at 25,60 and $100^{\circ} \mathrm{C}$, respectively. Comparing the $\eta_{E}$ values for the two specimen types it may be said that $\eta_{E}$ is not affected by the presence of the weldline. The modulus retention ratio or the weldline integrity parameter as it is commonly known (the ratio of the modulus of a specimen with a weldline to that of a specimen without a weldline) ranged between 0.98 and 0.95 and showed no systematic variation with respect to either temperature or fibre volume fraction of fibres.

It has been shown [4] that the modulus of a specimen with weldline $\left(E_{c w}\right)$ may be represented by the relationship given by Equation (8):

$E_{c w}=\frac{E_{c} E_{w}}{E_{w}-\left(E_{w}-E_{c}\right) z}$

where $E_{w}$ is modulus of the material inside the weldline, $E_{c}$ modulus of the material outside the weldline and $z$ is a dimensionless parameter whose value depends on the ratio $L_{w} / L_{0}$ where $L_{w}$ is width of the weldline and $L_{0}$ is the length of the specimen. Previous studies [1-4] using the same mould geometry indicated that whilst fibres inside the weldline region are predominantly aligned with their long axis parallel to the weldline (i. e. perpendicular to the mould-fill direction and the direction of the applied tensile stress), outside the weldline region they are predominantly aligned in the same direc-

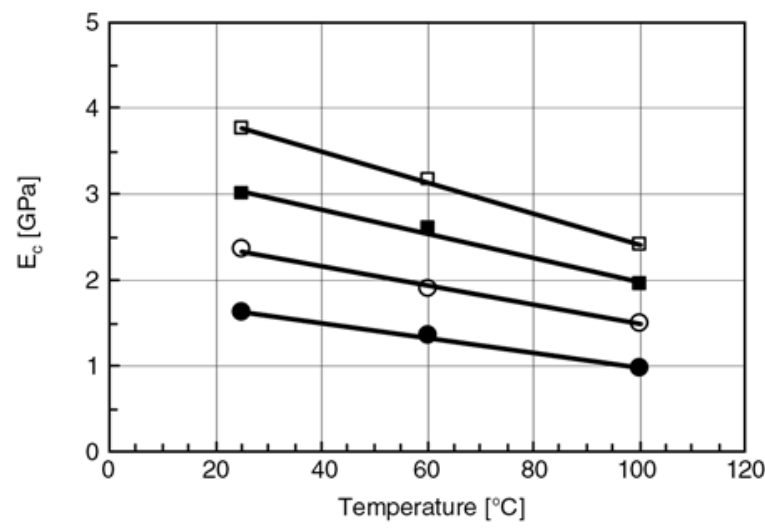

Figure 5. Effect of fibre volume fraction on tensile modulus of weldline specimens (WLS) at $25(\bullet)$, 40 (o) and $100^{\circ} \mathrm{C}(\mathbf{-})$ tion as in the weldline free specimens. The off-axis alignment of fibres outside the weldline region and the transverse alignment of fibres inside the weldline region, implies that $E_{c} \gg E_{w}$. Also, since the width of the weldline region, $L_{w}$ was typically less than $1 \mathrm{~mm}$ and therefore much smaller than the overall length of the specimen $\left(L_{0}\right)$, the ratio $z$ becomes very small and therefore the second term in denominator of Equation (8) becomes small compared to $E_{w}$, thus indicating that $E_{c w} \approx E_{c}$, i. e., weldline has little effect on tensile modulus as observed in this study.

As for the variation of $E_{c w}$, with temperature, a linear trend as in Figure 5 was noted with no significant variation in the slopes due to weldline.

\subsection{Tensile strength}

\subsubsection{Effect of fibre concentration}

The effect of fibre volume fraction on tensile strength of weldline free specimens (WFS) is shown in Figure 6. Evidently, in the absence of weldline, tensile strength increases with increasing fibre concentration with a tendency to level off or reaching a maximum on approaching fibre concentration value of approximately $16 \% \mathrm{v} / \mathrm{v}$. The levelling off effect (or reaching a maximum) which is also noted in several other injection moulded glass reinforced polymer systems $[3,4,8,9]$ is mainly attributed to the separation distance between the fibres becoming sufficiently small so that the flow of the matrix material between fibres is severely restricted. This effect and the higher stress concentration in the matrix due to the greater number of

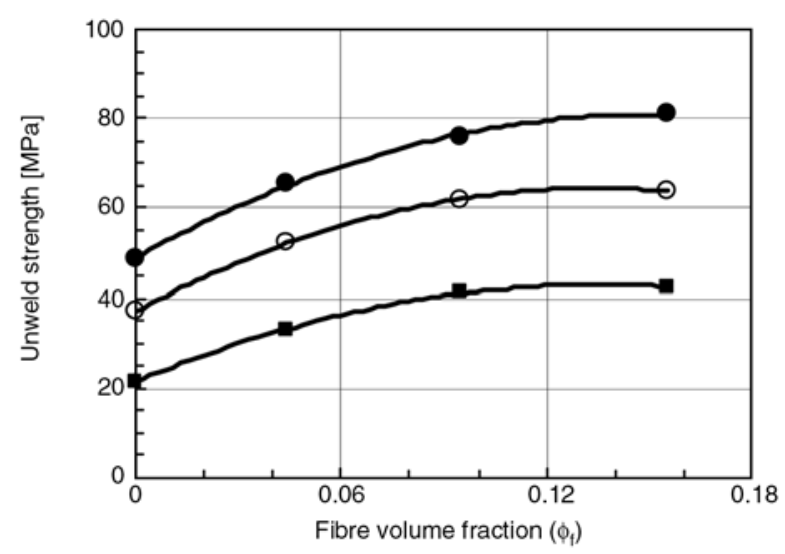

Figure 6. Effect of fibre volume fraction on tensile strength of weldline free specimens (WFS) at $25(\bullet), 40(\mathrm{o})$ and $100^{\circ} \mathrm{C}(\boldsymbol{\bullet})$ 
Table 3. Curve fitting parameters for composite strength as a function of fibre volume fraction at 25,60 , and $100^{\circ} \mathrm{C}$ for both WFS and WLS specimens

\begin{tabular}{|c|c|c|c|c|c|c|}
\hline \multirow{2}{*}{$\mathbf{T}\left[{ }^{\circ} \mathbf{C}\right]$} & \multicolumn{3}{|c|}{ WFS } & \multicolumn{3}{c|}{ WLS } \\
\cline { 2 - 7 } & $\mathbf{a}_{0}$ & $\mathbf{a}_{1}$ & $\mathbf{a}_{2}$ & $\mathbf{a}_{\mathbf{0}}$ & $\mathbf{a}_{1}$ & -593.39 \\
\hline 25 & 49.01 & 422.68 & -1401.6 & 44.48 & 88.81 & -946.20 \\
\hline 60 & 37.03 & 408.33 & -1524.2 & 34.10 & 164.92 & -858.80 \\
\hline 100 & 21.44 & 318.46 & -1176.1 & 20.03 & 171.48 & $\mathbf{a}_{\mathbf{2}}$ \\
\hline
\end{tabular}

fibre ends at high $\phi_{f}$, reduces the gain in strength which one would expect otherwise.

The nonlinear relationship seen in Figure 6 between tensile strength, $\sigma_{c}$ and the fibre volume fraction, $\phi_{f}$ can be described by a polynomial function given by Equation (9):

$\sigma_{c}=a_{0}+a_{1} \phi_{f}+a_{2} \phi_{f}^{2}$

where $a_{0}, a_{1}$ and $a_{2}$ are the curve fitting parameters whose values at the three test temperatures are given in Table 3. However, as illustrated in Figure 7 , tensile strength for fibre concentration values in the range 0 to $10 \% \mathrm{v} / \mathrm{v}$, can be reasonably assumed to increases linearly with $\phi_{f}$ (regression coefficients are in the range 0.96 to 0.98 ). The simplest model that may be used to predict a linear dependence between $\sigma_{c}$ and $\phi_{f}$ in short fibre composites is that of the 'modified rule-of-mixtures' which when rearranged can be expressed by Equation (10):

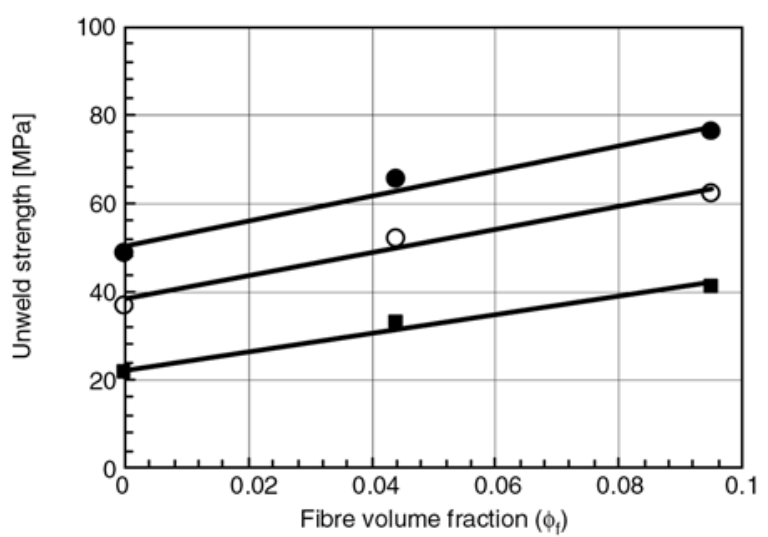

Figure 7. Effect of fibre volume fraction on tensile strength of weldline free specimens (WFS) with fibre concentration values in the range $0-9.5 \% \mathrm{v} / \mathrm{v}$ at $25(\bullet), 40(\mathrm{o})$ and $100^{\circ} \mathrm{C}$ $\sigma_{c}=\sigma_{m}+\left(\eta_{\sigma} \sigma_{f}-\sigma_{m}\right) \phi_{f}$

where $\sigma_{f}$ is the tensile strength of the fibre taken in this study as $2470 \mathrm{MPa}, \sigma_{m}$ is the tensile strength of the matrix and $\eta_{\sigma}$ is the overall fibre efficiency parameter for the composite strength taking into account the effects due to fibre length and orientation in the composite.

Using Equation (10) and the slope of the lines in Figure $7, \eta_{\sigma}$ values were evaluated. It can be seen from Table 4 that $\eta_{\sigma}$ values are considerably smaller than $\eta_{E}$ and likewise decrease with increasing temperature.

The overall efficiency parameter $\eta_{\sigma}$ like $\eta_{E}$ is the product of two efficiency parameters as given by Equation (11):

$\eta_{\sigma}=\eta_{L} \eta_{0}$

where $\eta_{L}$ is the fibre length and $\eta_{0}$ is the fibre orientation efficiency parameters for the composite strength. Using the $\eta_{0}$ values obtained via the modulus (see Table 2), values of $\eta_{L}$ for composite strength was evaluated as a function of temperature using Equation (11). It can be seen from Table 4 that $\eta_{L}$ for composite strength like for composite modulus decreases with increasing temperature.

Using the tabulated values of $\eta_{L}$ given in Table 4 and the average fibre lengths, the critical fibre lengths, $L_{c}$ was calculated for each composite as a function of temperature using the Kelly-Tyson relationship given by Equation (12) [18]:

$$
L_{c}=\frac{\bar{L}_{f}}{2 \eta_{L}}
$$

Table 4. Fibre efficiency parameters for composite strength as a function of fibre volume fraction at 25,60 , and $100^{\circ} \mathrm{C}$

\begin{tabular}{|c|c|c|c|c|c|c|c|c|c|}
\hline \multirow{2}{*}{$\phi_{\mathrm{f}}$} & \multicolumn{3}{|c|}{$\eta_{\sigma}$} & \multicolumn{3}{|c|}{$\eta_{0}$} & \multicolumn{3}{|c|}{$\eta_{\mathbf{L}}$} \\
\hline & $25^{\circ} \mathrm{C}$ & $60^{\circ} \mathrm{C}$ & $100^{\circ} \mathrm{C}$ & $25^{\circ} \mathrm{C}$ & $60^{\circ} \mathrm{C}$ & $100^{\circ} \mathrm{C}$ & $25^{\circ} \mathrm{C}$ & $60^{\circ} \mathrm{C}$ & $100^{\circ} \mathrm{C}$ \\
\hline 0.044 & 0.136 & 0.121 & 0.093 & 0.675 & 0.663 & 0.667 & 0.201 & 0.183 & 0.139 \\
\hline 0.095 & 0.136 & 0.121 & 0.093 & 0.677 & 0.664 & 0.669 & 0.201 & 0.182 & 0.139 \\
\hline 0.155 & 0.136 & 0.121 & 0.093 & 0.681 & 0.669 & 0.674 & 0.200 & 0.181 & 0.138 \\
\hline
\end{tabular}


Table 5. Fibre critical length as a function of fibre volume fraction at 25,60 and $100^{\circ} \mathrm{C}$

\begin{tabular}{|c|c|c|c|c|c|c|c|}
\hline \multirow{2}{*}{$\phi_{\mathbf{f}}$} & \multirow{2}{*}{$\mathbf{L}_{\mathbf{f}}$} & \multicolumn{3}{|c|}{$\eta_{\mathbf{L}}$} & \multicolumn{3}{c|}{$\mathbf{L}_{\mathbf{c}}[\mu \mathbf{m}]$} \\
\cline { 2 - 8 } & & $\mathbf{2 5}^{\circ} \mathbf{C}$ & $\mathbf{6 0}^{\circ} \mathbf{C}$ & $\mathbf{1 0 0}^{\circ} \mathbf{C}$ & $\mathbf{2 5}^{\circ} \mathbf{C}$ & $\mathbf{6 0}^{\circ} \mathbf{C}$ & $\mathbf{1 0 0}^{\circ} \mathbf{C}$ \\
\hline 0.044 & 110 & 0.201 & 0.183 & 0.139 & 274 & 301 & 396 \\
\hline 0.095 & 94 & 0.201 & 0.182 & 0.139 & 234 & 258 & 338 \\
\hline 0.155 & 83 & 0.200 & 0.181 & 0.138 & 208 & 229 & 301 \\
\hline
\end{tabular}

Results obtained from this analysis are presented in Table 5 where it can be seen that $L_{c}$ increases with temperature but decreases with increasing $\phi_{f}$ mainly due to the reduction in $\overline{L_{f}}$ with increasing $\phi_{f}$. It can be said that $\eta_{\sigma}$ is considerably smaller than $\eta_{E}$ simply because whilst $\eta_{E}$ depends on the average length of the fibres, $\eta_{\sigma}$ depends on both the average length as well as the critical fibre length which is lower.

\subsubsection{Effect of temperature}

The effect of temperature on the tensile strength of weldline free specimens is shown more explicitly in Figure 8 where it can be seen that it decreases with temperature in a linear manner. The effect of increasing $\phi_{f}$ is simply an upward vertical shift in tensile strength-temperature curve. It is also evident that tensile strength decreases with increasing temperature at a faster rate as fibre concentration is increased. The effect of temperature on tensile strength may be expressed by Equation (13):

$\sigma(T)=\sigma_{0}-\lambda T$

where values of $\sigma_{0}$ and $\lambda$ are both dependent upon $\phi_{f}$.

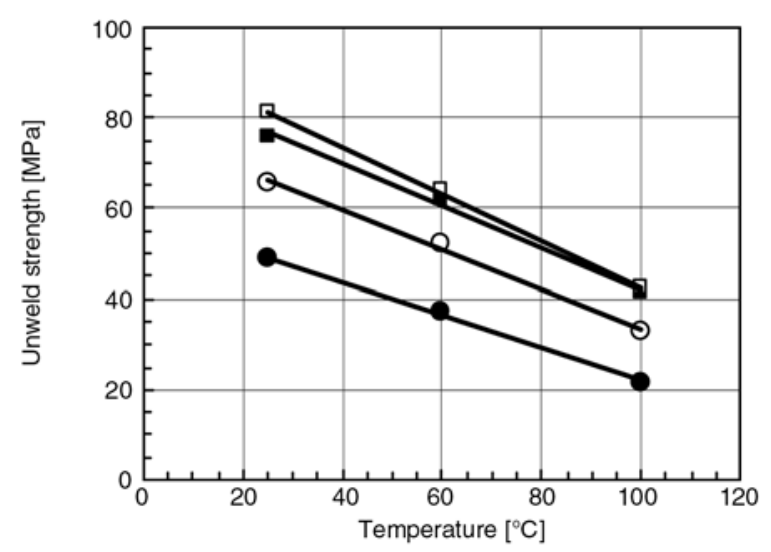

Figure 8. Effect of temperature on tensile strength of weldline free specimens (WFS) with concentration values (v/v) of $0 \%(\bullet), 4.4 \%(0), 9.5 \%(\bullet)$ and $15.5 \%(\square)$

\subsubsection{Effect of weldline}

Failure of the weldline specimens (WLS) was always at the weldline as shown in Figure 9. Figure 10 shows the effect of weldline strength $\left(\sigma_{c w}\right)$ as a function of fibre volume fraction, $\phi_{f}$ at the three temperatures selected in this study. It can be seen that $\sigma_{c w}$ increases initially and reaches a maximum at fibre concentration value of approximately $10 \% \mathrm{v} / \mathrm{v}$ before decreasing. As illustrated in Fig-

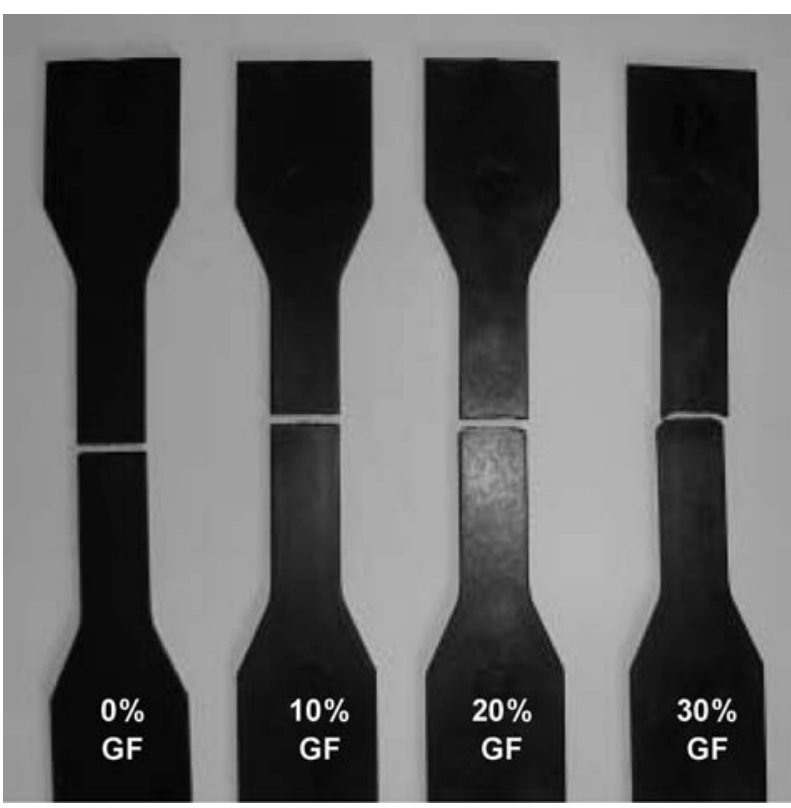

Figure 9. The broken weldline specimens (WLS) at $25^{\circ} \mathrm{C}$

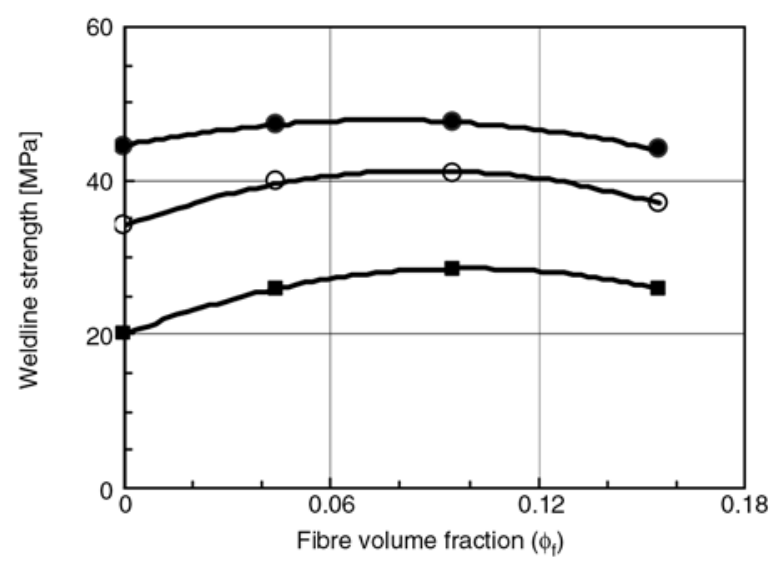

Figure 10. Effect of fibre volume fraction on tensile strength of weldline specimens (WLS) at $25(\bullet), 40(\mathrm{o})$, and $100^{\circ} \mathrm{C}(\boldsymbol{\bullet})$ 
ure 10, variation of $\sigma_{c w}$ with $\phi_{f}$ like $\sigma_{c}$ can also be expressed by Equation (14):

$\sigma_{c w}=a_{0}+a_{1} \phi_{f}+a_{2} \phi_{f}^{2}$

The values of $a_{0}, a_{1}$ and $a_{2}$ can also be found in Table 3. Using Equation (14) one can easily calculate weldline strength of the ABS composites for any fibre concentration value between 0 and $16 \% \mathrm{v} / \mathrm{v}$.

The effect of weldline on tensile strength was quantitatively expressed in terms of weldline integrity factor, $F_{\sigma}$ defined by Equation (15):

$F_{\sigma}=\frac{\text { Tensile strength of specimen with weldline }}{\text { Tensile strength of specimen without weldline }}$

Figures 11 and 12 show the variations of $F_{\sigma}$ with $\phi_{f}$ and temperature, respectively. It can be seen that $F_{\sigma}$ decreases with increasing $\phi_{f}$ but increases with increasing temperature. The observed reduction in tensile strength in the presence of weldline is attributed mainly to the reduction in the fraction of fibres crossing the weldline region, particularly at high concentration values of glass fibres. As a result, the material within the weldline region acted as if it was not reinforced. It is also evident from Figure 12 that $F_{\sigma}$ increases with temperature in a linear manner. As reflected by slope of the lines, $F_{\sigma}$ for composites shows greater temperature dependence than for the matrix. It is interesting to note that slope of $F_{\sigma}-T$ lines for the three composites shows no significant variation with respect to $\phi_{f}$, meaning

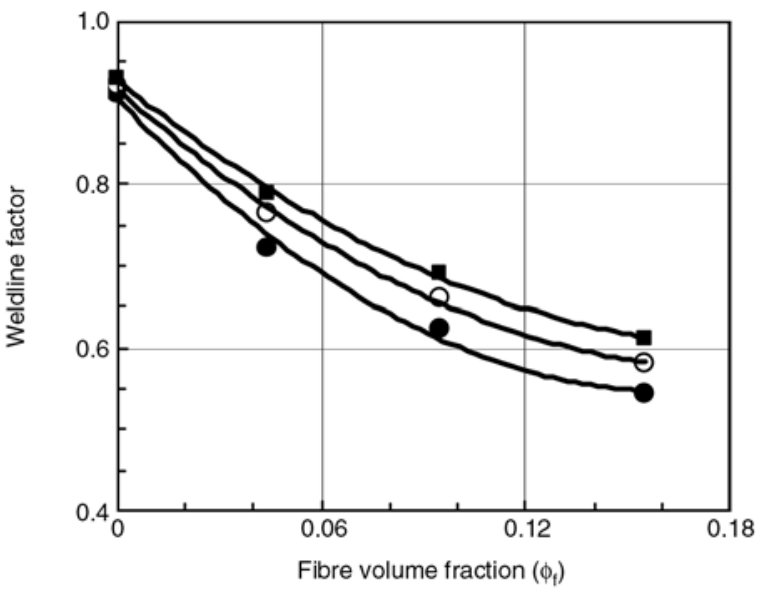

Figure 11. Effect of fibre volume fraction on weldline factor for tensile strength at $25(\bullet), 40(\mathrm{o})$ and $100^{\circ} \mathrm{C}(\mathbf{m})$

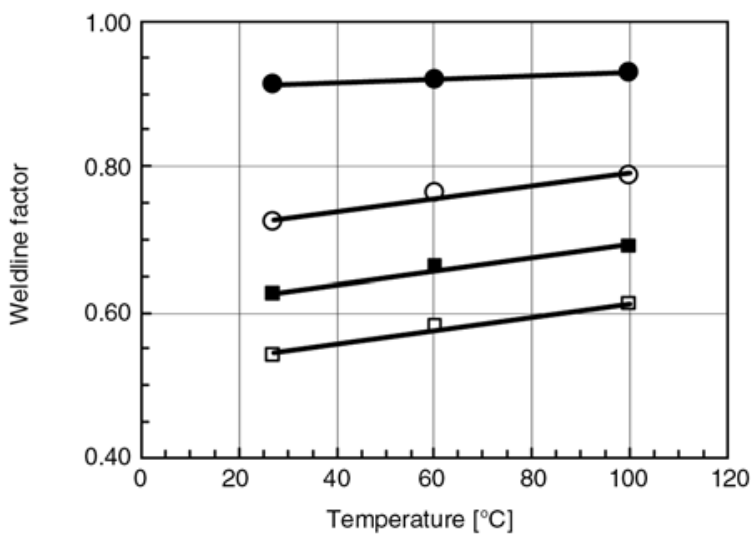

Figure 12. Effect of temperature on weldline factor for tensile strength with fibre concentration values $(\mathrm{v} / \mathrm{v})$ of $0 \%(\bullet), 4.4 \%(\mathrm{o}), 9.5 \%(\mathbf{})$ and $15.5 \%$ (ㅁ)

the rate at which $F_{\sigma}$ increases with temperature is not sensitive to $\phi_{f}$. It can be said, that the effect of $\phi_{f}$ is merely a downward vertical shift in the $F_{\sigma}-T$ line.

\subsection{Tensile strength and modulus}

The effect of temperature on tensile strength and modulus was analysed further using the general form of the relationship between shear stress, $\tau$ and shear modulus, $G$ as proposed by Kitagawa [19]. Kitagawa proposed a power law relation of the form given by Equation (16):

$$
\frac{T_{0} \tau}{T \tau_{0}}=\left(\frac{T_{0} G}{T G_{0}}\right)^{n}
$$

where $\tau_{0}$ and $G_{0}$ are the values of shear stress and shear modulus at some reference temperature $T_{0}$, respectively and $n$ is a temperature independent exponent. The shear properties $G$ and $\tau$ in Equation (16) were converted into tensile properties $E$ and $\sigma$ using Equation (17):

$\frac{\tau}{\tau_{0}}=\frac{\sigma}{\sigma_{0}}=\frac{E}{E_{0}}=\frac{G}{G_{0}}$

Substituting Equation (17) into Equation (16) and rearranging gives Equation (18):

$\ln \left(\frac{\sigma}{T}\right)=\ln \left[\left(\frac{T_{0}}{E_{0}}\right)^{n}\left(\frac{\sigma_{0}}{T_{0}}\right)\right]+n \ln \left(\frac{E}{T}\right)$

According to Equation (18) log-log plot of $(\sigma / T)$ versus $(E / T)$ should produce a straight line with the 


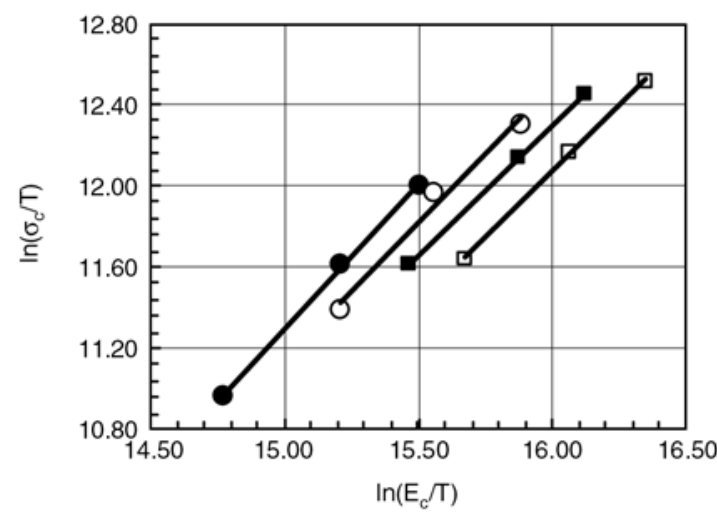

Figure 13. $\ln \left(\sigma_{c} / T\right)$ versus $\ln \left(E_{c} / T\right)$ according to Equation (20) for weldline free specimens (WFS) with fibre concentration values (v/v) of $0 \%(\bullet)$, $4.4 \%(0), 9.5 \%(-)$ and $15.5 \%$ ()

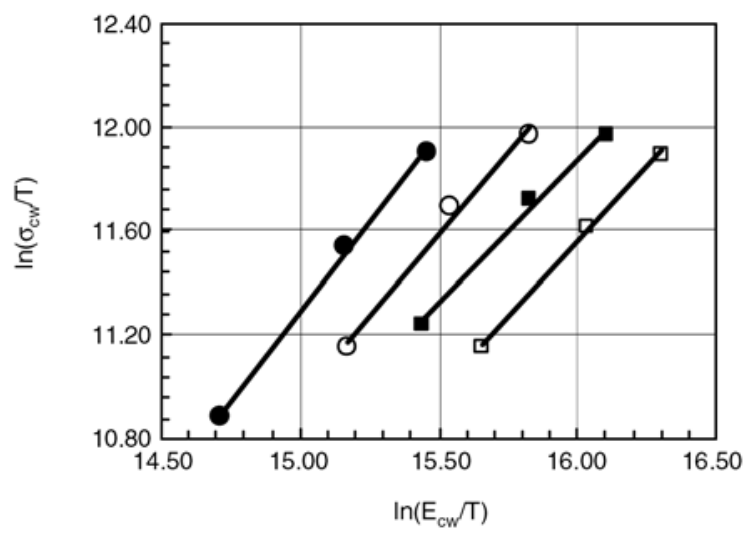

Figure 14. $\ln \left(\sigma_{c w} / T\right)$ versus $\ln \left(E_{c w} / T\right)$ according to Equation (20) for weldline specimens (WLS) with fibre concentration values $(\mathrm{v} / \mathrm{v})$ of $0 \%(\bullet)$, $4.4 \%(0), 9.5 \%(\bullet)$ and $15.5 \%$ ()

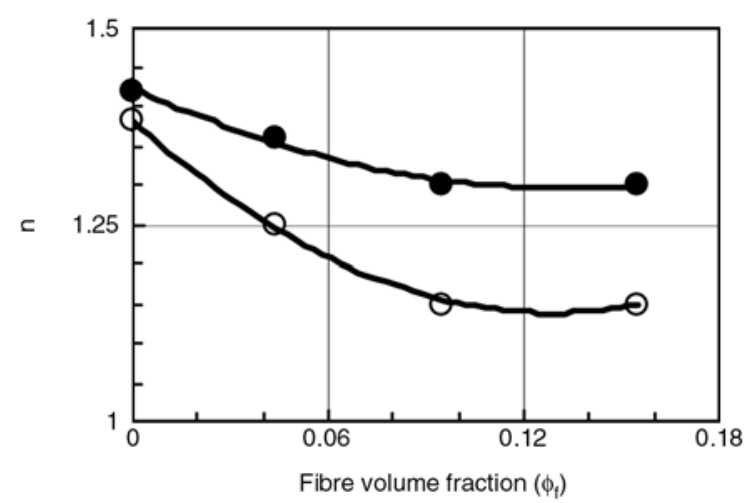

Figure 15. Exponent $\mathrm{n}$ versus volume fraction of fibres for WFS $(\bullet)$ and WLS (o)

slope of $n$. Figures 13 and 14 show log-log plots according to Equation (18) for both unweld and weld data respectively for the range of $\phi_{f}$ values studied in this work. It is found that weld and unweld data for the matrix and its composites follow Equation (18) remarkably well with regression coefficients of 0.996 or better. The values of $n$ obtained from the slope of the lines are plotted in Figure 15 as a function of $\phi_{f}$ where it can be seen that for the composite system studied here, exponent $n$ deceases with increasing $\phi_{f}$ for both weld and unweld specimens with unweld specimens exhibiting higher $n$ particularly for the three composites.

\section{Conclusions}

The effect of temperature (between 25 and $100^{\circ} \mathrm{C}$ ), fibre concentration (between 0 and $15.5 \% \mathrm{v} / \mathrm{v}$ ) and weldline on tensile strength and modulus of ABS reinforced with short glass fibres was investigated. The following observations were made:

- Tensile modulus increased linearly with increasing $\phi_{f}$ and decreased linearly with increasing temperature. The linear dependence between tensile modulus and $\phi_{f}$ obeyed modified rule of mixtures.

- Presence of weldline had no significant effect on tensile modulus. Weldline integrity factor was in the range 0.98 to 0.95 .

- Tensile strength of weldline free specimens increased with increasing $\phi_{f}$ in a nonlinear manner but decreased with temperature in a linear manner. For fibre concentration values in the range $0-10 \% \mathrm{v} / \mathrm{v}$, variation of tensile strength with $\phi_{f}$ was reasonably linear and obeyed the modified rule of mixtures for strengths.

- Weldline strength increased with increasing $\phi_{f}$ in a nonlinear manner reaching a maximum at fibre concentration of about $10 \% \mathrm{v} / \mathrm{v}$.

- Weldline factor for strength decreased with increasing $\phi_{f}$ but increased linearly with increasing temperature.

- The fibre efficiency parameters for composite strength and modulus decreased with increasing temperature. The efficiency parameter for composite strength was greater than for composite modulus.

- The effect of temperature on tensile modulus and strength for both WFS and WLS was satisfactorily modelled using the Kitagawa power law relationship. The power law exponent was affected by the fibre concentration and its value for WFS was higher than for WLS. 


\section{References}

[1] Chrysostomou A., Hashemi S.: Mechanical properties of injection-moulded styrene maleic anhydride (SMA). Part II: Influence of short glass fibres and weldlines. Journal of Materials Science, 33, 44914501 (1998).

[2] Nabi Z. U., Hashemi S.: Influence of short glass fibres and weldlines on the mechanical properties of injection-moulded acrylonitrile-styrene-acrylate copolymer. Journal of Materials Science, 33, 2985-3000 (1998).

[3] Hashemi S.: Influence of temperature on weldline strength of injection moulded short glass fibre styrene maleic anhydride polymer composites. Plastics, Rubber and Composites, 31, 1-7 (2002).

[4] Hashemi S., Lepessova Y.: Temperature and weldline effect on tensile properties of injection moulded short glass fibre PC/ABS polymer composite. Journal of Materials Science, 42, 2652-2662 (2007).

[5] Necar M., Irfan-ul-Haq M., Khan Z.: Temperature and weld-line effects on mechanical properties of CPVC. Journal of Materials Processing Technology, 142, 247-255 (2003).

[6] Fu S. Y., Lauke B., Mader E., Yue C. Y., Hu X.: Tensile properties of short-glass-fiber- and short-carbonfiber-reinforced polypropylene composites. Composites, Part A, 31, 1117-1125 (2000).

[7] Fisa B.: Mechanical degradation of glass fibres during compounding with polypropylene. Polymer Composites, 6, 232-341 (1985).

[8] Thomason J. L.: Micromechanical parameters from macromechanical measurements on glass reinforced polypropylene. Composites Science and Technology, 62, 1455-1468 (2002).

[9] Thomason J. L.: Micromechanical parameters from macromechanical measurements on glass reinforced polyamide 6,6. Composites Science and Technology, 61, 2007-2016 (2001).
[10] Debondue E., Fournier J-E., Lacrampe M-F., Krawczak P.: Wedlines in injection-molded reinforced thermoplastics: Mechanical performance improvement through intrusion induced fibre reorientation. Polymer and Polymer Composites, 12, 373-381 (2004).

[11] Sanschagrin B., Gauvin R., Fisa B., Vu-Khanh T.: Weldlines in injection moulded polypropylene: Effect of filler shape. Journal of Reinforced Plastics and Composites, 9, 194-208 (1990).

[12] Meddad A., Fisa B.: Weldline strength in glass fiber reinforced polyamide 66. Polymer Engineering and Science, 35, 893-901 (1995).

[13] Akay M., Barkley D.: Flow-aberrations and weld lines in glass-fibre reinforced thermoplastics injection mouldings. Plastics, Rubber and Composites Processing and Applications, 20, 137-149 (1993).

[14] Nadkarni V. M., Ayodhya S. R.: The influence of knitlines on the tensile properties of fibreglass reinforced thermoplastics. Polymer Engineering and Science, 33, 358-367 (1993).

[15] Fisa B., Rahmani M.: Weldline strength in injection molded glass fibre-reinforced polypropylene. Polymer Engineering and Science, 31, 1330-1336 (1991).

[16] Cox H. L.: The elasticity of strength of paper and other fibrous materials. British Journal of Applied Physics, 3, 72-79 (1952).

[17] Krenchel H.: Fibre reinforcement. Akademisk Forlag, Copenhagen (1964).

[18] Kelly A., Tyson W. R.: Tensile properties of fibre reinforced metals. Journal of the Mechanics and Physics of Solids, 13, 329-350, (1965).

[19] Kitagawa M.: Power law relationship between yield stress and shear modulus for glassy polymers. Journal of Polymer Science: Polymer Physics Edition, 15, 1601-1611 (1977). 